\title{
Polycarbonate based multifunctional self-sensing 2D and 3D printed structures for aeronautic applications
}

\author{
P. Costa ${ }^{1,2^{*}}$, J. R. Dios ${ }^{3}$, J. Cardoso ${ }^{1,4}$, J. J. Campo ${ }^{3}$, C. R. Tubio ${ }^{5}$, B.F. Gonçalves ${ }^{1,6}$, N. \\ Castro $^{5}$, S. Lanceros-Méndez ${ }^{5,7^{* *}}$ \\ 1-Center of Physics, University of Minho, Campus de Gualtar, 4710-057 Braga, Portugal \\ 2-Institute for Polymers and Composites IPC, University of Minho, 4804-533 Guimarães, Portugal \\ 3-GAIKER Technology Centre, Basque Research and Technology Alliance (BRTA), Parque Tecnológico, Ed 2020, 48170 Zamudio, \\ Spain \\ 4-Institute of Science and Innovation for Bio-Sustainability (IB-S), University of Minho, Braga, 4710-057, Portugal \\ 5-BCMaterials, Basque Center for Materials, Applications and Nanostructures, UPV/EHU Science Park, 48940 Leioa, Spain \\ 6-INL-International Iberian Nanotechnology Laboratory, Braga, 4715-330, Portugal \\ 7-IKERBASQUE, Basque Foundation for Science, 48013 Bilbao, Spain \\ E-mail: *pcosta@fisica.uminho.pt; **senentxu.lanceros@bcmaterials.net \\ Received xxxxxx \\ Accepted for publication $\mathrm{xxxxxx}$ \\ Published xxxxxx
}

\begin{abstract}
Different polycarbonate materials have been reinforced with carbon nanotubes to tune electrical conductivity and to induce piezoresistive self-sensing capabilities. Further, the composites were processed by solvent casting and fused deposition modelling (filament for 3D printing) methods. An electrical conductivity percolation threshold of $\approx 0.3 \mathrm{wt}$ \% has been found for solvent casted films, whereas samples processed by 3D printing show higher thresholds, $\approx 2$ wt.\%, presenting all samples a similar maximum electrical conductivity $\left(\sigma \approx 1 \times 10^{-3} \mathrm{~S} / \mathrm{m}\right)$, thermal and chemical properties. Overall mechanical properties are larger for the solvent cast films concerning the 3D printed ones, particularly the elongation at break. The piezoresistive sensibility, obtained after 4-point-bending and uniaxial strain experiments, shows gauge factors up to 1.7 , independently of the processing method. The functionality of the materials has been demonstrated by the implementation of an airplane wing section model with self-sensing capabilities. Two implemented strategies showed the suitability of the developed materials for realtime monitoring of the wing mechanical deformation.
\end{abstract}

Keywords: Polycarbonate, piezoresistive, structural health monitoring, 3D printing, self-sensing.

\section{Introduction}

Polymers and polymer composites have been increasingly investigated for the development and application of multifunctional lightweight materials for structures [1], including sensing and/or actuating properties [1, 2]. In particular, efforts on additive manufacturing of multifunctional polymer-based materials have largely increased in recent years for applications in structural health monitoring (SHM) in automotive [3], aeronautics [2, 4], biomedical (implants or prosthetics) [1, 4], electronics [3, 5] or even toy industries $[1,5]$. 
Additive manufacturing by 3D printing allows us to produce structures from 3D model data for rapid prototyping and direct digital manufacturing of devices [4, 6, 7], is strongly developed in the last decades with the possibility to acquire $3 \mathrm{D}$ printers for home use $[1,4,6]$. With these novel printing methods, it is conceivable to create simple and complex object geometries composed of one or multiple materials, allowing applications not easily reached with traditional manufacturing methods, that are limited in terms of geometries and materials characteristics $[4,8]$.

One of the most challenging fields of additive manufacturing is to implement materials with advanced properties: structural reinforcements (mechanical, thermal or surface treatments) and the introduction of properties for sensing applications, such as piezoelectric [3, 9], piezoresistive [1, 3], thermosensitive $[3,9]$, capacitive $[1,9]$ and magnetic $[3,9]$ properties, among others $[9,10]$. Polymer composites reinforced with nanofillers are largely used as structural components [4, 9], in biomedical [11] and multifunctional devices $[9,10]$.

High-performance polymers and multifunctional materials can be achieved by tailoring the overall properties of the composites, combining the specific properties of the polymers with the functionality of the reinforcement nanofillers. For example, in the automotive or aerospace industries, structural components are using insulating polymers composites with electrically conductive nanofillers to provide a tailored electrical response or electrical response variations [4]. Thus structural health monitoring systems (SHM) are developed where components can be a part of or the full structure while allowing the real-time measuring of structural damage of these components [12]. Piezoresistive or capacitive sensing capabilities can be thus added to polymer composites components for SHM from small to large scales [2, 9], piezoresistive ones being among the most used in this context [13]. Polymer-based piezoresistive sensors can be also tuned for their mechanical properties, allowing large strains, low hysteresis and large electro-mechanical sensitivity, quantified by the Gauge Factor $\left(G F=\frac{\Delta R}{R_{0}} / \varepsilon\right)$, that can be larger than 100 for conductive polymers [14-16] and above 120 for polymer composites [15, 17]. Polymer blends [15, 18, 19] and nanocarbonaceous filler reinforced thermoplastics $[4,19,20]$ are thus increasingly used for additive manufacturing and 3D printing [6, 19, 21]. This trend is experiencing a further increase in the scope of the Industry 4.0 and Internet of things (IoT) concepts, where multifunctional materials for sensing are in demand $[22,23]$.

Thermoplastics reinforced with conductive nanocarbonaceous fillers have proven to be among the best ways to tailor the piezoresistive properties of polymer-based sensors [5, 24, 25] Due to their higher electrical conductivity and larger aspect ratio $[10,16]$, carbon nanotubes are the most suitable fillers to reinforce the insulator polymers. Besides low percolation thresholds, the piezoresistive sensibility of the CNT composites is large $[17,25]$ and can be comparable to the one obtained in semiconducting materials [24]. The tunnelling effect of the CNTs network embedded into the polymer matrix plays a major role in the composite piezoresistivity [26].

Polycarbonate (PC) is a thermoplastic polymer widely used in polymer processing by both solvent casting and melt-based techniques, in the form of pristine polymer and polymer composites [4, 27]. PC reinforced with CNTs show piezoresistive properties and low percolation threshold [28]. Mechanically, the composites are characterized by the highest impact resistance among all thermoplastics [12].

In this context, the present work presents the development of multifunctional polycarbonate-based polymer composites for sensing applications. Polycarbonate is used as a host matrix and was processed by solvent casting and filament extruder for 3D printing. The polymer and the corresponding composites reinforced with multi-walled CNTs were prepared by solvent-casting and FDM methods using two approaches: processing by using the CNTs in powder form and by using a masterbatch with 15 wt.\% of CNTs embedded into polycarbonate. Morphological, chemical, thermal, mechanical and electrical properties were evaluated, as well as the 
piezoresistive performance. Finally, the functional applicability of the materials was demonstrated by developing a self-sensing model of the wing section of an airplane.

\section{Experimental}

\subsection{Materials}

The polymer used was polycarbonate (PC) with reference Makrolon® 2205 from Covestro. It has good UV resistance, Young's Modulus of $2.4 \mathrm{GPa}$, glass transition temperature at $145^{\circ} \mathrm{C}$ and melt temperature processing at $280-320{ }^{\circ} \mathrm{C}$. Further, the melt flow index value is 20 (MFI, ISO1133; g/10 $\min , 300{ }^{\circ} \mathrm{C}, 1.2 \mathrm{Kg}$ ).

Powder multi-walled carbon nanotubes (CNTs) from Nanocyl, with reference NC7000, were used, having an average diameter and length of $9.5 \mathrm{~nm}$ and $1.5 \mu \mathrm{m}$, respectively, and a purity of $90 \%$. These CNTs have a volume resistivity $(\rho)$ of $10^{-6} \Omega . \mathrm{m}$, which is ideal for their use as reinforcing material for conductive polymer nanocomposites. Masterbatch of 15 wt.\% CNTs dispersed in polycarbonate with reference Plasticyl PC1501 (in the form of pellets) was supplied by Nanocyl. In fact, plastics in the form of masterbatch are the ideal solution for industry manufacturing due to the easier and safe processing. The CNTs used as powder and in masterbatch are the same ones (Nanocyl NC7000).

Dichloromethane (DCM) HPLC grade $99.8 \%$ from Fisher Chemical was used to dissolve the polymer and to disperse CNTs.

\subsection{Samples preparation and processing methods}

The pristine polymer and the corresponding composites were processed using two different approaches: solvent casting (thin films by doctor blade) and extruded filament for 3D printing technique (Table 1). In the solvent casting method, the PC polymer was reinforced with CNTs in the form of powder and masterbatch, in order to compare the overall properties. Extruded filament for 3D printing was prepared just from CNT/PC masterbatch.
For solvent casting, DCM was used to dissolve the PC matrix and disperse the CNTs at different filler contents both for CNTs in powder and masterbatch form. Pristine PC and composites with filler contents of 0.5, 1, 2 and 5 percentage weight (wt.\%) of CNTs were prepared either by adding the CNT in the powder form or by diluting the masterbatch. The different materials combinations for both processing techniques are presented in Table 1. DCM was selected because of its lower toxicity when compared to other PC solvents such as dimethylformamide or chloroform [29, 30].

Table 1- Samples processed by solvent casting and FDM and the corresponding nomenclature used along the manuscript.

\begin{tabular}{|c|c|c|c|c|}
\hline $\begin{array}{c}\text { CNTs } \\
(\text { wt.\%) }\end{array}$ & \multicolumn{2}{|c|}{ Solvent Casting } & $\begin{array}{c}\text { CNTs } \\
\text { (wt.\%) }\end{array}$ & $\begin{array}{c}\text { FDM } \\
\text { Filament } \rightarrow \\
\text { 3D print }\end{array}$ \\
\hline 0 & $\mathrm{PC}$ & $\mathrm{PC}$ & & \\
0.5 & $0.5 \mathrm{P} / \mathrm{PC}$ & $0.5 \mathrm{M} / \mathrm{PC}$ & 0 & $\mathrm{PC}$ \\
1 & $1 \mathrm{P} / \mathrm{PC}$ & $1 \mathrm{M} / \mathrm{PC}$ & 2 & $2-3 \mathrm{D} / \mathrm{PC}$ \\
2 & $2 \mathrm{P} / \mathrm{PC}$ & $2 \mathrm{M} / \mathrm{PC}$ & 5 & $5-3 \mathrm{D} / \mathrm{PC}$ \\
5 & $5 \mathrm{P} / \mathrm{PC}$ & $5 \mathrm{M} / \mathrm{PC}$ & & \\
\hline CNTs & Powder & Masterbatch & & Masterbatch \\
\hline
\end{tabular}

For the preparation of the samples by solvent casting, the corresponding content of CNTs (Table 1 for powder or masterbatch fillers) was placed in a glass flask with the solvent and kept in an ultrasound bath for $3 \mathrm{~h}$ to obtain filler disaggregation and dispersion. Then, PC (Makrolon 2205) was added to the solution and magnetically stirred until complete dissolution $\left(2 \mathrm{~h}\right.$ at $\left.25^{\circ} \mathrm{C}\right)$. The PC:DCM ratio used was 1:6 (g:mL) for pristine PC and the corresponding composites. Relevant steps of the composite preparation are presented in Figure 1.

After complete dissolution, the solutions were deposited on a glass substrate and spread using a doctor blade bar coater Elcometer 4340 Automatic Film Applicator with speed control. The obtained films were dried at $25{ }^{\circ} \mathrm{C}$ for $12 \mathrm{~h}$ until total solvent evaporation. The thickness of the films after evaporation was $(28 \pm 8) \mu \mathrm{m}$, measured using a digital micrometer Fischer Dualscope 603-478. 


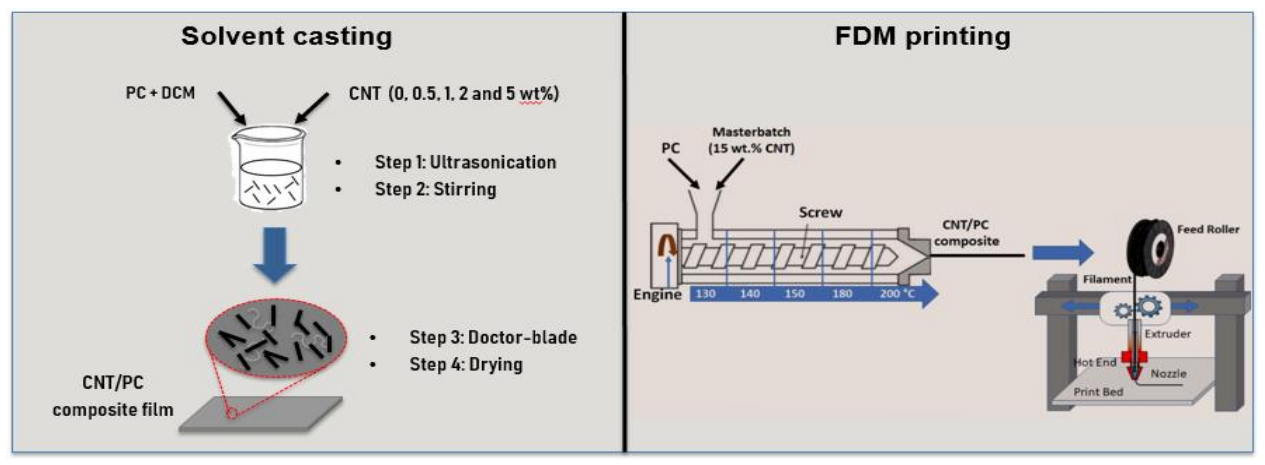

Figure 1- Schematic representation of the preparation of PC and composite materials by solvent casting (left) and by 3D printing (right) from the extruded filament.

Further, PC and the masterbatch PC1501 with 15 wt.\% of CNTs diluted to obtain the different filler contents $(0,2$ and 5 wt.\%) were used for developing filaments for 3D printing by extrusion (Figure 1 right). The corresponding polymer and masterbatch were first dried $\left(120^{\circ} \mathrm{C}\right.$ for $\left.4 \mathrm{~h}\right)$ and extruded in a corotating twin-screw extruder LEISTRITZ micro 27 GL-36 $\mathrm{D}$ with the screw speed between 55 and $150 \mathrm{rpm}$, the temperatures varied from 160 to $270{ }^{\circ} \mathrm{C}$, from feed to die zones, respectively. The samples were then cooled for $2 \mathrm{~h}$ at $\approx 25^{\circ} \mathrm{C}$. The filament for FDM was prepared with $(2.8 \pm 0.2)$ $\mathrm{mm}$ of diameter.
To test the ability to print the material by FDM, the functional formulations with 2 and 5 wt.\% CNTs content were printed with a desktop two-head Voladora 3D printer from Tumaker (Figure 2A). Dog-bone shaped specimens (Figure 2B) with 0, 2 and 5 wt.\% CNTs were 3D printed, as shown in Figure 2A and $\mathrm{B}$, with the dimensions $151.5 \mathrm{~mm}$ of length and $2.5 \mathrm{~mm}$ thickness, according to the type V specimens of the standard ASTM D638-14 [31], but with increased tab's width to avoid breaking in the grips. Figure 2 illustrates the geometry and dimensions of solvent casted and printed specimens.

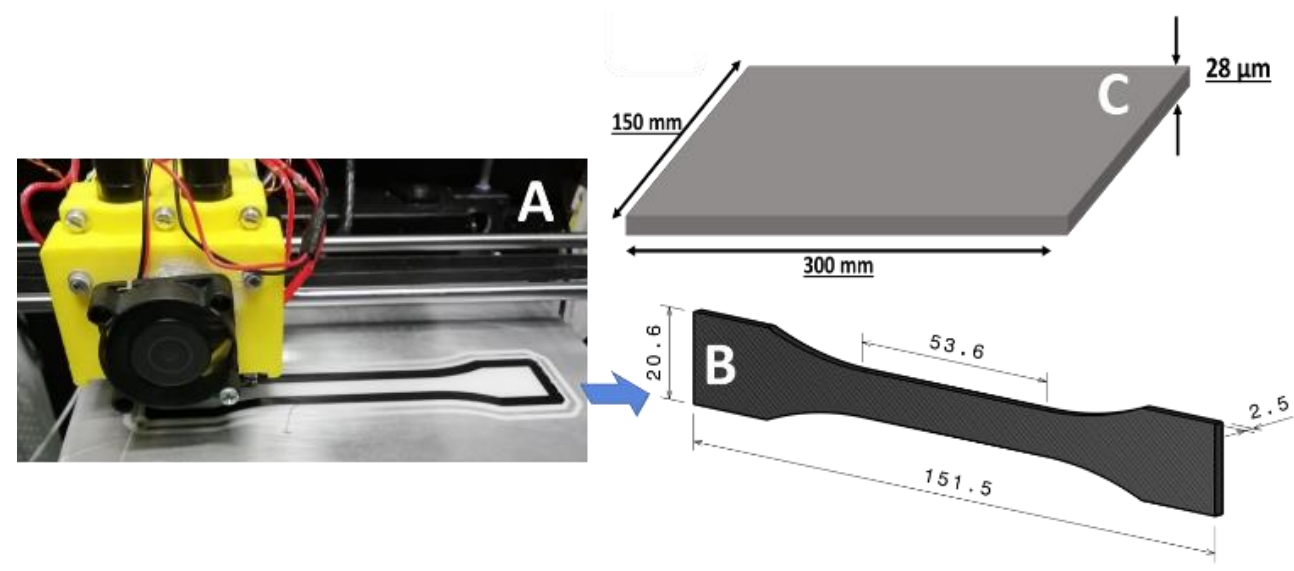

Figure 2- Format and dimensions of the prepared samples: A) 3D-Printer Voladora (Tumaker) and B) printed samples (dimensions in mm). C) Films prepared by solvent casting.

\subsection{Samples characterization}

Scanning electronic microscopy (SEM Hitachi S-4800) was used to evaluate the surface and cross-section morphology of 
the different materials as a function of the processing method and filler content. The samples were previously gold-coated $(\approx 10 \mathrm{~nm}$ of thickness) using an Emitech K550X sputter coater. The obtained SEM images were performed at an accelerating voltage of $10 \mathrm{kV}$.

Molecular vibrations characterization of the samples was carried out using a Fourier transformed infrared spectroscopy (FTIR) system (Jasco FTIR-4100 equipment) in the attenuated total reflectance mode (ATR) from 4000 to $600 \mathrm{~cm}^{-1}$, with 64 scans at a resolution of $4 \mathrm{~cm}^{-1}$.

Thermal analysis of the materials was performed by differential scanning calorimetry (DSC) and thermogravimetric analyses (TGA), using the Metter-Toledo TGA/DSC1 equipment. TGA measurements were conducted from 25 up to $600{ }^{\circ} \mathrm{C}$ at a rate of $10{ }^{\circ} \mathrm{C} / \mathrm{min}$ under a nitrogen atmosphere (inert gas to avoid the oxidation of the samples). Then, between 600 to $800{ }^{\circ} \mathrm{C}$, the samples were heated in an oxygen atmosphere at $10{ }^{\circ} \mathrm{C} / \mathrm{min}$ to completely degrade all organic material. DSC measurements were performed to evaluate the thermal transitions of the polymer and composites. The heating scans were performed for all samples from -70 to $200{ }^{\circ} \mathrm{C}$ at a rate of $10{ }^{\circ} \mathrm{C} / \mathrm{min}$.

The mechanical characteristics of the samples were evaluated in specimens with dimensions of approximately $40 \mathrm{~mm} \times 10$ $\mathrm{mm} \times 0.028 \mathrm{~mm}$ for solvent cast samples and approximately $150 \mathrm{~mm} \times 25 \mathrm{~mm} \times 2.5 \mathrm{~mm}$ for 3D printed samples. Tensile tests were performed at room temperature $\left(25^{\circ} \mathrm{C}\right)$ using a Shimadzu model AG-IS universal test machine (500 N load cell; acquisition software Trapezium $X$ v1.4.0) with a strain rate of $1 \mathrm{~mm} / \mathrm{min}$, in agreement with the ASTM D638-14 [31]. A total of five specimens were tested for each material.

The electrical resistivity $(\rho)$ of the samples was evaluated with an automated Keithley 487 picoammeter/voltage source. The voltage/current curves were measured by applying voltages from -10 to $+10 \mathrm{~V}$ with a step of $1 \mathrm{~V}$. The electrical resistance in a volume of the PC and composites was calculated from the linear slope of the current-voltage curves. Previously, all samples were gold-coated by magnetron sputtering (Polaron SC502) with round contacts with $5 \mathrm{~mm}$ of diameter deposited in both sides of the samples. The electrical resistivity $(\rho)$ was calculated from the obtained resistance $(\mathrm{R})$ and the geometrical characteristics of the samples, following the equation:

$$
\rho=\frac{R A}{l}
$$

where $A$ is the area of electrodes and $l$ the distance between them (thickness of the material). The electrical conductivity is the inverse of resistivity $(\sigma=1 / \rho)$.

Electromechanical measurements were carried out by measuring, simultaneously, the mechanical deformation (Shimadzu AG-IS) applied to the samples and the DC electrical resistance (Agilent 344401A multimeter) variations. Measurements were performed under 4-point-bending (for all samples) and uniaxial strain (for 3D printed samples) mechanical solicitations, as illustrated in Figure 3. Under 4point-bending and uniaxial strain the electrical resistance variations were measured by placing two conductive contacts on the surface of the samples, as represented in Figure 3. Electrical contacts were painted with conductive silver paint (Agar Scientific AGG3790) over the width of the samples (20 $\mathrm{mm}$ ) with a distance of 6 and $10 \mathrm{~mm}$ between electrodes for 4-point-bending and tensile tests, respectively. For the 4point-bending experiments, the samples were glued to a rectangular PET substrate $(100 \mathrm{~mm}$ x $20 \mathrm{~mm})$ using doublesided duct tape. The piezoresistive tests were performed at deformations from 0.1 to $5 \mathrm{~mm}$ using strain rates of $0.5,2$ and $5 \mathrm{~mm} / \mathrm{min}$ for 4-point-bending (Figure 3A) and between 1 to $5 \%$ of strain at $0.5,1$ and $2 \mathrm{~mm} / \mathrm{min}$ (Figure $3 \mathrm{~B}$ ) in the tensile test mode. 


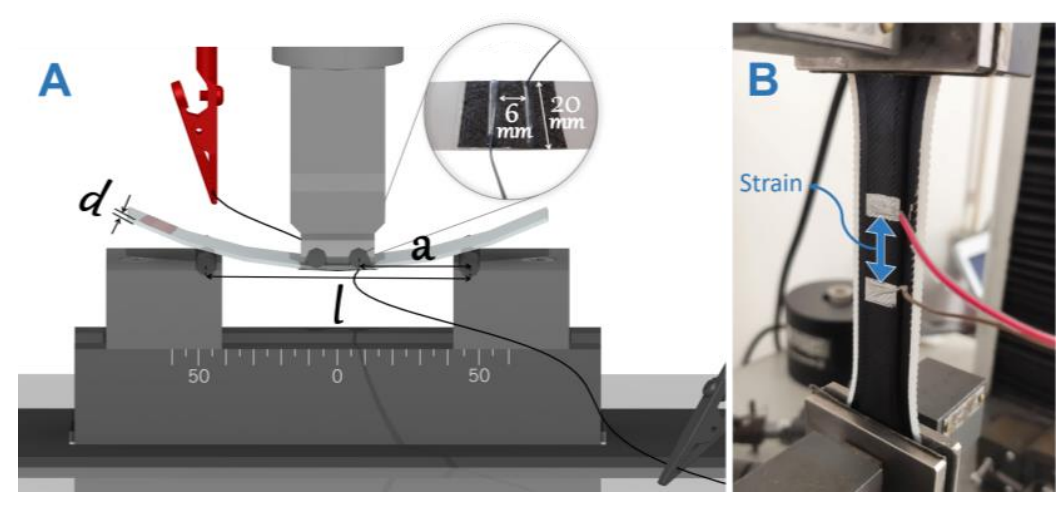

Figure 3- Experimental setup for A) 4-point-bending and B) uniaxial tensile test mode measurements.

The piezoresistive response of the samples was quantified by the Gauge Factor $(G F)$ using equation 2 [32]:

$$
G F=\frac{d R / R_{0}}{d l / l_{0}}=\frac{d R / R_{0}}{\varepsilon}+(1+2 v)
$$

where $R$ is the electrical resistance, $R_{0}$ the initial resistance and $d R$ the resistance variations. The mechanical strain $\varepsilon=d l / l_{0}$ ( $l$ is the initial length and $d l$ the relative length change) and $v$ is the Poisson coefficient.

The horizontal mechanical deformation of the samples can be obtained from the applied vertical strain in the 4-point bending tests by [33]:

$$
\varepsilon=\frac{3 d z}{5 a^{2}}
$$

where $d$ is the thickness of the sample, $z$ is the applied displacement and $a$ is the distance between the first and second points of the four-point bending system. For the 4-pointbending mode measurement, $a=15 \mathrm{~mm}$ and $l=3 a$ (Figure 3A).

The geometrical factor $(1+2 v)$ contribution to the $G F$ (equation 2) depends on the properties of the materials and shows a maximum contribution of $G F \approx 2$ for ideal elastomers with a $v=0.5$ [34], decreasing to near $G F \approx 1.7$ for thermoplastic polymers with a $v=0.35$ [33].

\section{$2.43 D$ printed airplane section model}

The potential of the developed materials for applications was demonstrated by developing 3D structures with self-sensing capability.
Two approaches were implemented: a) the sensing material was coated in the structural part, fabricated by $3 \mathrm{D}$ printing of commercial acrylonitrile butadiene styrene (ABS); and b) the whole structure was developed in a self-sensing material.

Specifically, the proof-of-concept (Figure 4 for theoretical model and 5 for the experimental conditions) consisted of the evaluation of the mechanical behaviour and sensing capabilities of a simplified stiffened skin, which was designed so that it could be $3 \mathrm{D}$ printed to be used in a small airplane or drone wings. The wing consists of a flat-bottomed airfoil with two stiffeners ("I" and "C" shaped), a typical design in aircraft and related aerospace vehicles [35]. The geometry and dimensions are illustrated in Figure 4.

Since the critical mechanical requirement for both the upper surface of the wing and stingers is their compression strength [36], the mechanical behaviour was analysed under compressive loads. This experimental procedure also allows to demonstrate the concept, that can be further extended to other types or mechanical solicitations that may be present in a wing.

\subsubsection{Numerical simulations by finite element modelling}

Finite element mechanical analyses were performed using the FEM software Abaqus/CAE 6.13 by creating a linear elastic (isotropic) material model of the $3 \mathrm{D}$ wing. The stress-strain relationship is given by [37]: 


$$
\left\{\begin{array}{l}
\varepsilon_{11} \\
\varepsilon_{22} \\
\varepsilon_{33} \\
\varepsilon_{12} \\
\varepsilon_{13} \\
\varepsilon_{23}
\end{array}\right\}=\left[\begin{array}{cccccc}
1 / E & -v / E & -v / E & 0 & 0 & 0 \\
-v / E & 1 / E & -v / E & 0 & 0 & 0 \\
-v / E & -v / E & 1 / E & 0 & 0 & 0 \\
0 & 0 & 0 & 1 / G & 0 & 0 \\
0 & 0 & 0 & 0 & 1 / G & 0 \\
0 & 0 & 0 & 0 & 0 & 1 / G
\end{array}\right]\left\{\begin{array}{l}
\sigma_{11} \\
\sigma_{22} \\
\sigma_{33} \\
\sigma_{12} \\
\sigma_{13} \\
\sigma_{23}
\end{array}\right\}
$$

The elastic properties are completely defined by giving Young's modulus, $E$, and the Poisson's ratio, $v$. The shear modulus, $G$, can be expressed in terms of $E$ and $v$ as $G=$ $\frac{1}{2} \mathrm{E} /(1+v)$.

The aim was to evaluate the mechanical behaviour of the structure under compressive loads, so that it is possible to visualize the areas susceptible to larger deformations, and therefore where the electrodes can be placed for proper structural variations monitoring. Compressive loadings were applied by the means of pressure ( $5 \mathrm{MPa}$ ) on the upper surface of the wing (Figure 4A).

The boundary conditions consisted of fully fixing the bottom surface of the wing (Figure 4B), therefore $\mathrm{U} 1=\mathrm{U} 2=\mathrm{U} 3=\mathrm{UR} 1=\mathrm{UR} 2=\mathrm{UR} 3=0$ (i.e., all displacement, $\mathrm{U}$, and rotation, UR, degrees of freedom are zero).

The elastic properties for the model were the ones of the PC reinforced with 2 wt.\% CNT content printed by FDM, with Young's modulus being $E=2.4 \mathrm{GPa}$ and the Poisson's ratio $v=$ 0.37 , estimated from [38].

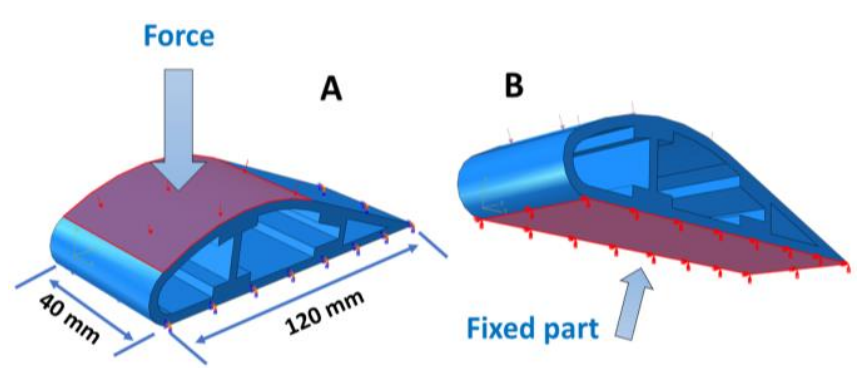

Figure 4- Loading (A) and boundary conditions (B) -indicated by the red regions- of the the wing design with $120 \mathrm{~mm} \times 40$ mm of length and width, respectively.

Finally, the wing model was simulated as a homogeneous solid and meshed using quadratic tetrahedral elements of type
C3D10 and a total number of nodes of 122818 (76237 elements).

\subsubsection{Functionalization of the wing and experimental evaluation}

Following the conclusions obtained from the finite element simulations allowing to determine the best places to position the electrodes within the upper skin of the wing model. The experimental setup (Figure 5) was set to reproduce the loading and boundary conditions previously simulated (fixed bottom part of the wing and a compressive load applied on the upper part). Conductive electrodes using silver paint (from Agar scientific with reference AGG3790) were placed in the areas of the wing illustrated in Figure 5C and D. Copper wires were used to connect the silver electrodes to the electronic readout system to measure the resistance variations. The surface layout of the sensors (two top electrodes) has $\approx 3 \mathrm{~mm} \times 0.5$ $\mathrm{mm}$ of length and distance between them, respectively. Three sensors were placed on the wing model, where sensors 1 and 3 ( $\mathrm{S} 1$ and $\mathrm{S} 3$ ) are parallel along the wing and sensor 2 (S2) is perpendicular to it, as shown in Figure 5.

As previously mentioned, the functional performance of the CNTs reinforced PC composites was proven using two approaches: i) the structural part of the wing fabricated in ABS and coated with PC and ii) an entire functional wing fabricated using the PC composite. Both composites have 2 wt.\% CNT content as an active layer and for the entire wing (ABS/2$3 \mathrm{D} / \mathrm{PC}$ and $2-3 \mathrm{D} / \mathrm{PC}$ shown in Figure $5 \mathrm{C}$ and 5D, respectively). Thus, both strategies allow to development of SHM skin layers or fully SHM structural parts. 


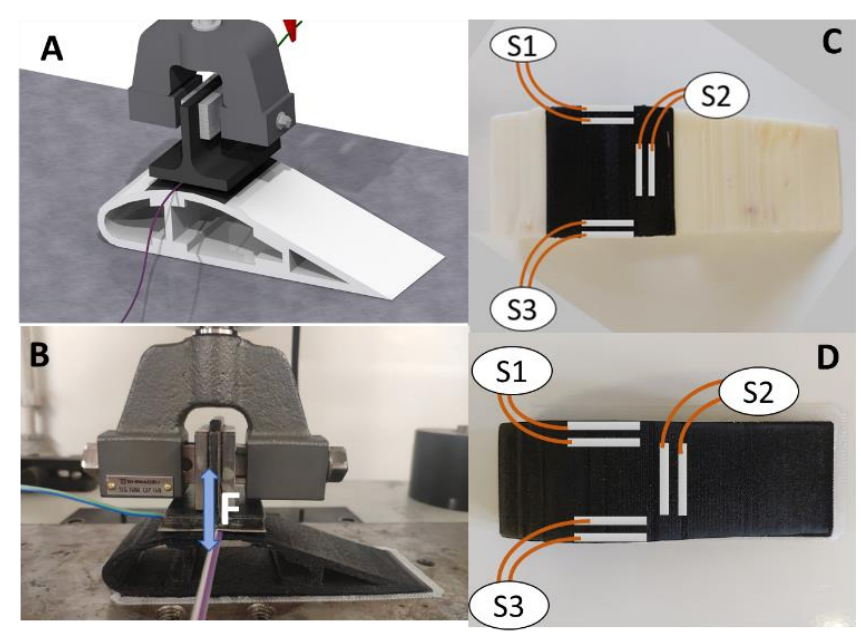

Figure 5- Illustration (3D rendering (A)) of the setup for the electromechanical tests of the wing under compression loading B) and of the piezoresistive measurements on the section of the wing for ABS/2-3D/PC (C) and 2-3D/PC (D) using 3 different sensors ( $\mathrm{S} 1, \mathrm{~S} 2$ and $\mathrm{S} 3$ ), placed in the critical areas in which the deformation is the largest.

\section{Results and discussion}

\subsection{Morphological and structural properties}

The morphology of the samples prepared by solvent casting is presented in the SEM images of Figure 6. As shown for the composites with 5 wt.\% of CNTs prepared from CNT powder and masterbatch, the individual CNTs dispersion showed similar for the composites prepared from masterbatch (Figure $6 \mathrm{~A}$ and $\mathrm{B}$ ) and the obtained for ones prepared from the CNT power (Figure 6C and D). The CNT distribution within PC is similar for the samples with the other filler contents, the only different being the increasing number of CNT with increasing filler content.

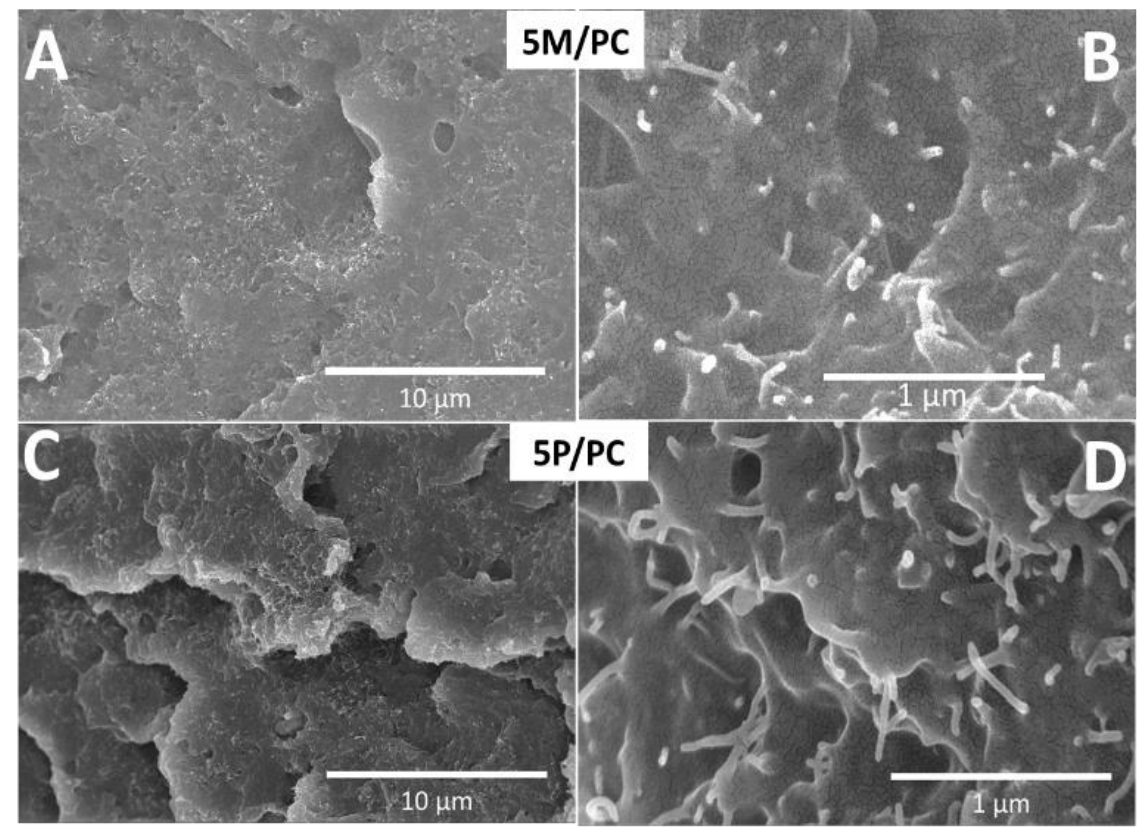

Figure 6- Cross-section SEM images of the CNT/PC films with 5\% CNTs content prepared from the masterbatch (A and B) and from the CNT powder (C and D).

Figure 6 reveals a uniform distribution of CNTs within the PC matrix in all samples, being more individual CNTs dispersion when an ultrasound bath is used for the preparation of the films. Ultrasounds bath effectively deagglomerates the 
powder CNT in DCM solution, as reported in related composite materials [39]. On the other hand, small clusters are found in the composites prepared from the CNT/PC masterbatch. Further, all composites show similar dispersion independently of the filler content, with all samples showing a homogenous microstructure with the absence of large defects or voids. Further, the dispersion of the fillers in the 3D printed samples is also similar to the one obtained in Figures $6 \mathrm{~A}$ and $\mathrm{B}$ for the solvent castes films, as a result of being prepared from the masterbatch.
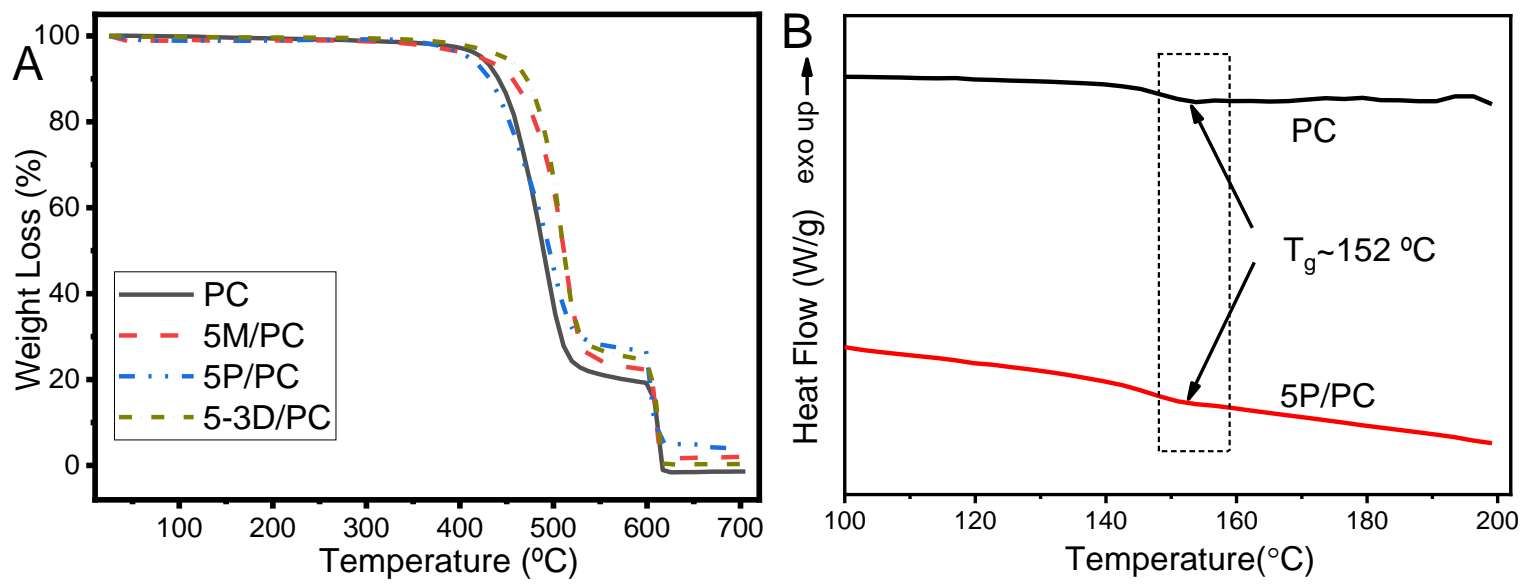

Figure 7- A) TGA characterization of the PC and composites with 5 wt.\% CNT content for the different filler form and processing method and B) DSC thermograms of the PC and composite with $5 \mathrm{wt} \% \mathrm{CNT}$ content (for masterbatch sample). The TGA and DSC spectra are similar for the rest of the PC composites.

Figure 7A shows the results for the PC matrix and the composites with 5 wt.\% CNTs. Pristine PC shows an initial thermal degradation near $280{ }^{\circ} \mathrm{C}$ and a maximum degradation temperature $\left(\mathrm{T}_{\mathrm{DTG}}\right)$ at $491{ }^{\circ} \mathrm{C}$, similar to the value previously reported for this PC [40, 41]. PC reinforced with 5 wt.\% CNTs shows a slight increase in the degradation temperature to $\mathrm{T}_{\mathrm{DTG}} \approx 511{ }^{\circ} \mathrm{C}[40,41]$. Literature reports about $20 \%$ of residual mass at $600{ }^{\circ} \mathrm{C}$ in TGA measurements under nitrogen atmosphere [40, 42], which is completely degraded in oxygen atmosphere from $600{ }^{\circ} \mathrm{C}$ up to $800^{\circ} \mathrm{C}$ as shown in Figure 7A. Thus, the reinforcement of the PC matrix with CNTs slightly increases the thermal stability of the composite [42], increasing the thermal degradation temperature in PC
The thermal characteristics of the samples were studied by TGA and DSC until complete polymer degradation and up to $200^{\circ} \mathrm{C}$, respectively, as shown in Figure 7. The obtained TGA thermograms of PC and composites with 5 wt.\% filler content (Figure 7A) were prepared using both processing methods (solvent casting and 3D printing) and CNT form (powder or masterbatch). composites, in agreement with the SEM results of the homogeneous dispersion of the CNTs embedded in PC [41]. With respect to the DSC thermograms, the glass transition temperature $\left(\mathrm{T}_{\mathrm{g}}\right)$ of $\mathrm{PC}$ and $5 \mathrm{P} / \mathrm{PC}$ is similar, $\mathrm{T}_{\mathrm{g}} \approx 151^{\circ} \mathrm{C}$, for all samples (even for composite with $5 \mathrm{wt}$ \% CNTs processed by masterbatch and 3D printed ones, data not shown) [43, 44]. Thus, the inclusion of the CNT does not influence the glass transition of the PC matrix, independently of the filler content or processing conditions.

Chemical analysis through the FTIR spectra presented in Figure 8 shows the same characteristic absorption bands (Table 3) [45, 46] for PC and composites, independently of CNTs content or processing method. 


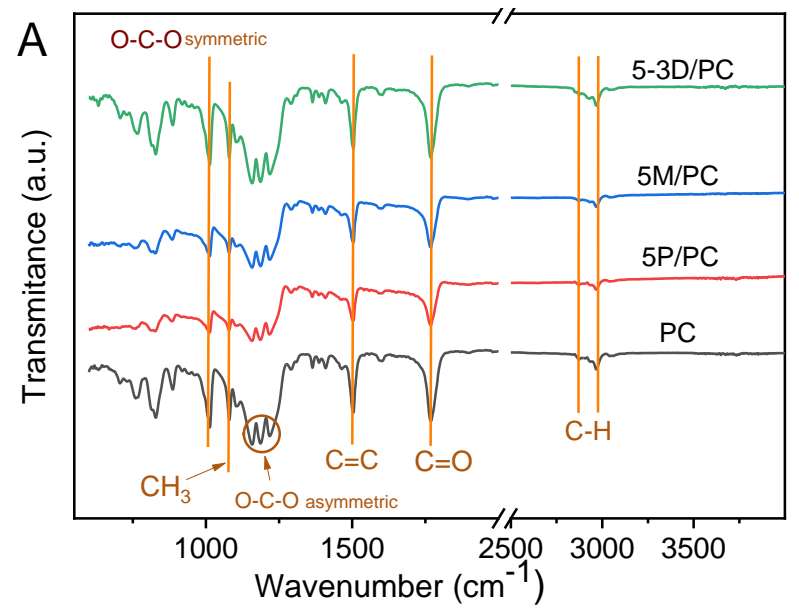

\begin{tabular}{|c|c|}
\hline B $\begin{array}{c}\text { Characteristic } \\
\text { bands }\end{array}$ & $\begin{array}{c}\text { Absorption peaks } \\
\left(\mathbf{c m}^{-1}\right)\end{array}$ \\
\hline $\begin{array}{l}\text { Symmetric } \\
\mathrm{O}-\mathrm{C}-\mathrm{O}\end{array}$ & 1015 \\
\hline$-\mathrm{CH}_{3}$ & 1081 \\
\hline $\begin{array}{c}\text { Asymmetric } \\
\mathrm{O}-\mathrm{C}-\mathrm{O}\end{array}$ & $1158 ; 1186 ; 1217$ \\
\hline $\mathrm{C}=\mathrm{C}$ & 1506 \\
\hline $\mathrm{C}=\mathrm{O}$ & 1769 \\
\hline $\mathrm{C}-\mathrm{H}$ & $2873 ; 2976$ \\
\hline
\end{tabular}

Figure 8- A) FTIR spectra of pristine PC and composites loaded with 5\% CNTs between 600 to $400 \mathrm{~cm}^{-1}$. B) Table 3Characteristic absorption bands of the PC [45, 46].

The characteristic absorption bands of PC have been detected and are presented in Table 3. Briefly, $\mathrm{C}-\mathrm{H}$ aromatic ring deformation, $\mathrm{C}=\mathrm{O}$ carbonate group deformation, $\mathrm{C}=\mathrm{C}$ vibrations, asymmetric and symmetric O-C-O carbonate group deformations and the $-\mathrm{CH}_{3}$ vibrations have been identified [45, 46]. All samples, independently of CNT content or preparation conditions, show the same FTIR spectra, which leads to the conclusion that neither the loading of CNTs nor the processing method influences the structure of the PC [47].

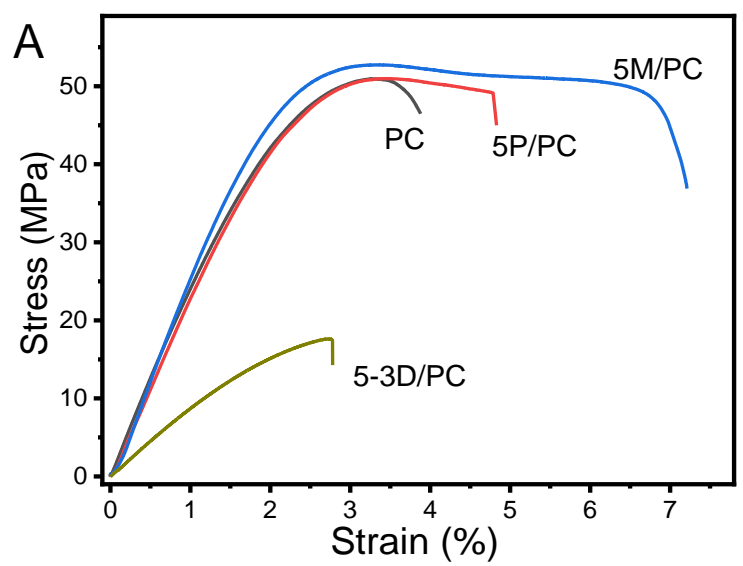

\subsection{Mechanical properties}

The mechanical properties of the samples were evaluated by the uniaxial quasi-static stress-strain experiments presented in Figure 9A. The mechanical parameters, elongation at break, Young modulus (E), ultimate tensile strength (UTS), elongation at yield and elongation at break of the PC and composites prepared by the different processing methods are presented in Figure 9B.

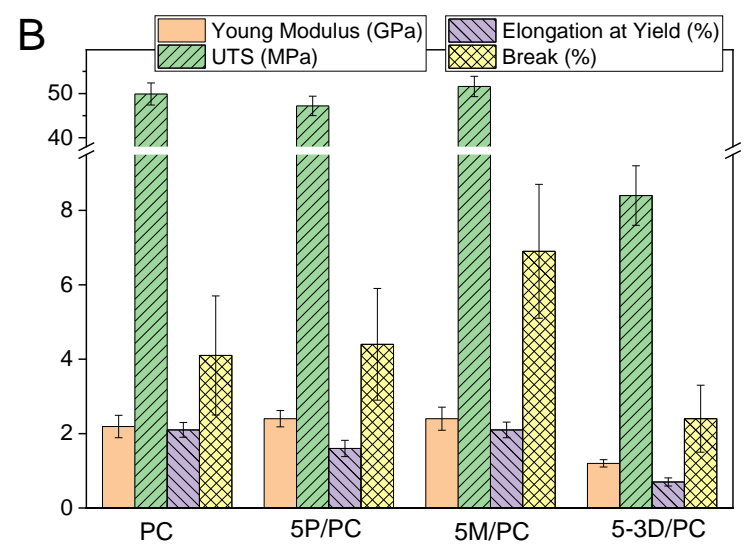

Figure 9- Mechanical properties of the PC and composites prepared by solvent casting and 3D printed, for pristine PC and composites with 5 wt.\% CNTs. B) Tensile mechanical properties of the PC composites: Young modulus (E (MPa)), Ultimate Tensile Strain (UTS (MPa)), Elongation at yield (\%) and Elongation at break (\%) of all samples. 
The maximum elongation of the pristine PC is near $4.1 \%$, presenting about $2 \%$ of elongation at yielding. The elongation at break increases for the composites prepared by solvent casting (increasing to $4.4 \%$ for $5 \mathrm{P} / \mathrm{PC}$ samples using powder CNTs) or masterbatch (increasing to $6.9 \%$ for $5 \mathrm{M} / \mathrm{PC}$ samples) and decreases for 3D printed composites (decreasing to $2.4 \%$ ). The filler materials act as reinforcement material in solvent cast samples, mainly for elongation at break and Young modulus (about $10 \%$ for solvent cast composites with 5 wt. $\%$ CNTs, decreasing near $50 \%$ for 3D composites). Low CNT contents in PC matrixes increase the mechanical properties of samples for solution composites [48, 49] and decrease for materials prepared from the melt Ultimate Tensile Stress at break (UTS) and yield strain is similar for pristine PC and solvent cast composites. The UTS is about $50 \mathrm{MPa}$ for all samples, decreasing for the 3D printed materials. Thus, the overall mechanical properties of the 3D printed samples decrease when compared to solvent casted ones, which is related to the layer-by-layer deposition, interlayer characteristics and filament orientation of the processed structures [50, 51]. Layer-by-layer interface weakens the mechanical properties of the composites.

\subsection{Electrical properties}

The current-voltage characteristic curves for the samples prepared from the CNT powder and the electrical conductivity as a function of filler content for the samples processed by different preparation methods are presented in Figure 10. Low percolation thresholds are achieved for the samples prepared by solvent casting (lower than 0.5 wt.\% CNT content) when compared to $3 \mathrm{D}$ printed composites, in which the percolation threshold is at about 2 wt.\% CNT content. Thus, the processing method strongly influences the conductive properties of the CNT/PC composites.

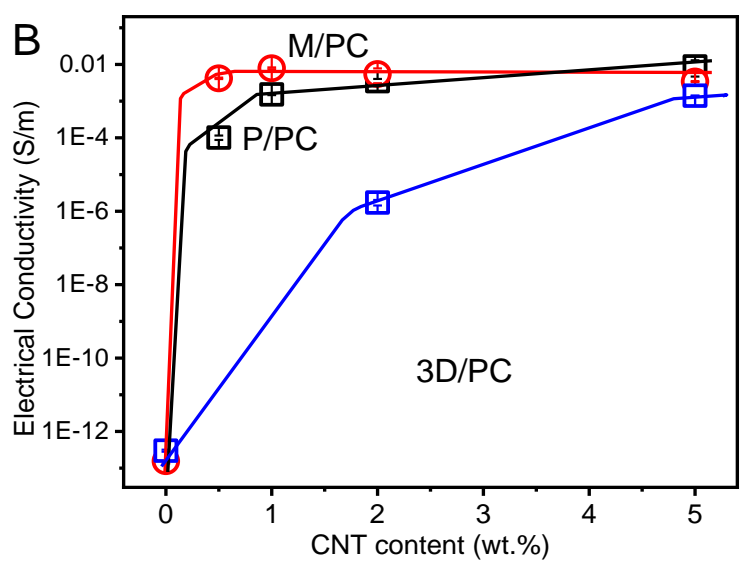

Figure 10- A) Current/voltage (I-V) measurements between -1.0 and 1.0 V for the CNT/PC samples prepared by solvent casting as a function of CNTs content and B) electrical conductivity for all samples as a function of CNT content.

the maximum conductivity of the composites, which is similar

Functional and conducting polymer composites reinforced with nanocarbonaceous materials are among the key issues for the development of smart materials for devices [24, 52], the properties strongly depending on the processing method, filler content and dispersion. In fact, the dispersion method is the factor that most influences the percolation threshold but not for all samples with the largest CNT content (Figure 10B). 3D printed materials present a larger percolation threshold (about 2 wt.\%) than solvent cast ones (lower than 0.25 for powder or masterbatch CNTs). The electrical conductivity of the composites has been addressed also in the literature as a function of the processing method [53, 54], where the 3D printed samples show a decrease of one order of magnitude 
compared to solvent cast samples, for the same filler content. Lower CNT dispersion and filler alignment leads to a decrease in the electrical conductivity of the composites when prepared by $3 \mathrm{D}$ printing when compared with solvent casted samples.

Thus, when processed from the melt, larger filler contents are needed for obtaining a given electrical conductivity in comparison with samples prepared by solvent casting. In addition, the mechanical properties of the sample prepared by solvent casting are improved with the inclusion of the CNT fillers, unlike for the melt printed 3D samples. On the other hand, melt printing allows the tailor-made design of structural components or part of final devices, which is more difficult using solvent methods.
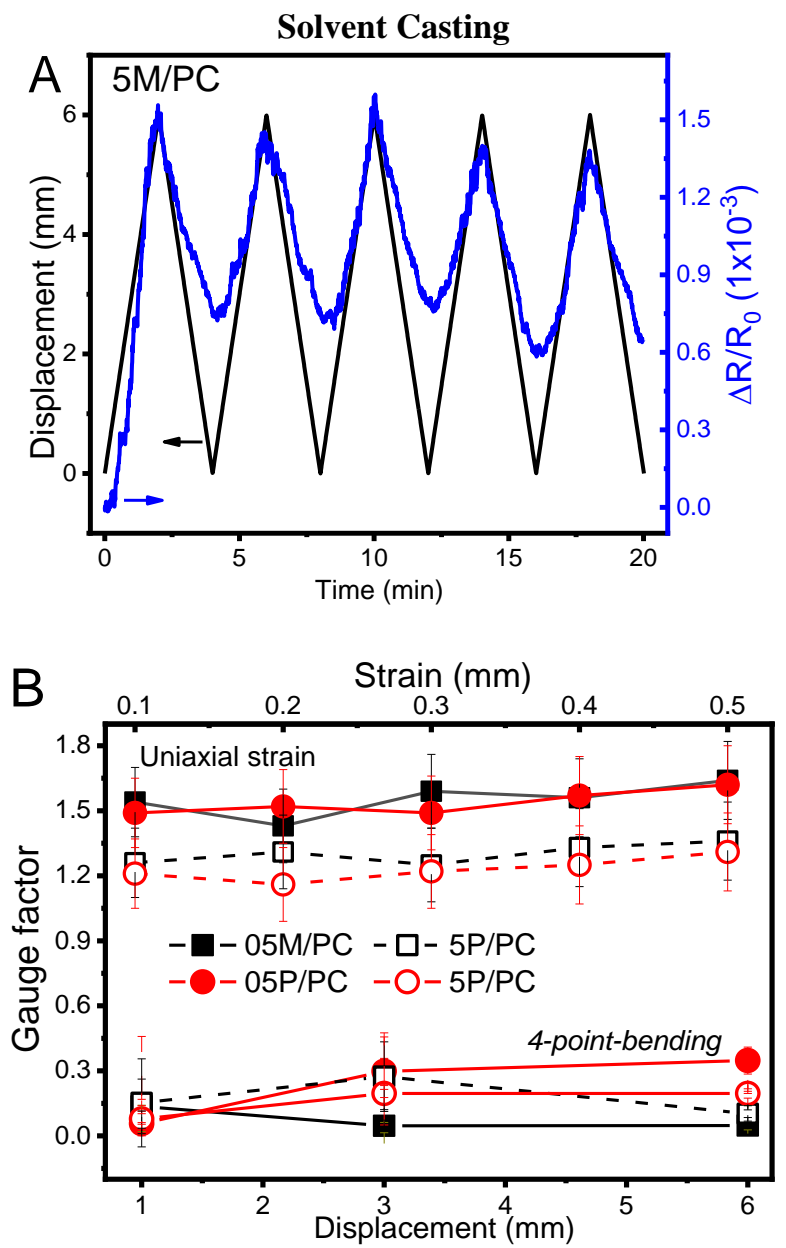

\subsection{Piezoresistive response}

$\mathrm{CNT} / \mathrm{PC}$ composites show suitable mechanical properties and low electrical percolation threshold, and thus, are good candidates as functional piezoresistive material. In addition, the piezoresistive response can be obtained in composite materials processed either by solvent casting or by $3 \mathrm{D}$ printing, as presented in Figure 11. The piezoresistive measurements were performed in the composites with the lowest and highest fillers contents $(0.5$ and $5 \mathrm{wt} . \%$ for solvent casted samples and 2 and 5 wt.\% for extruded ones).
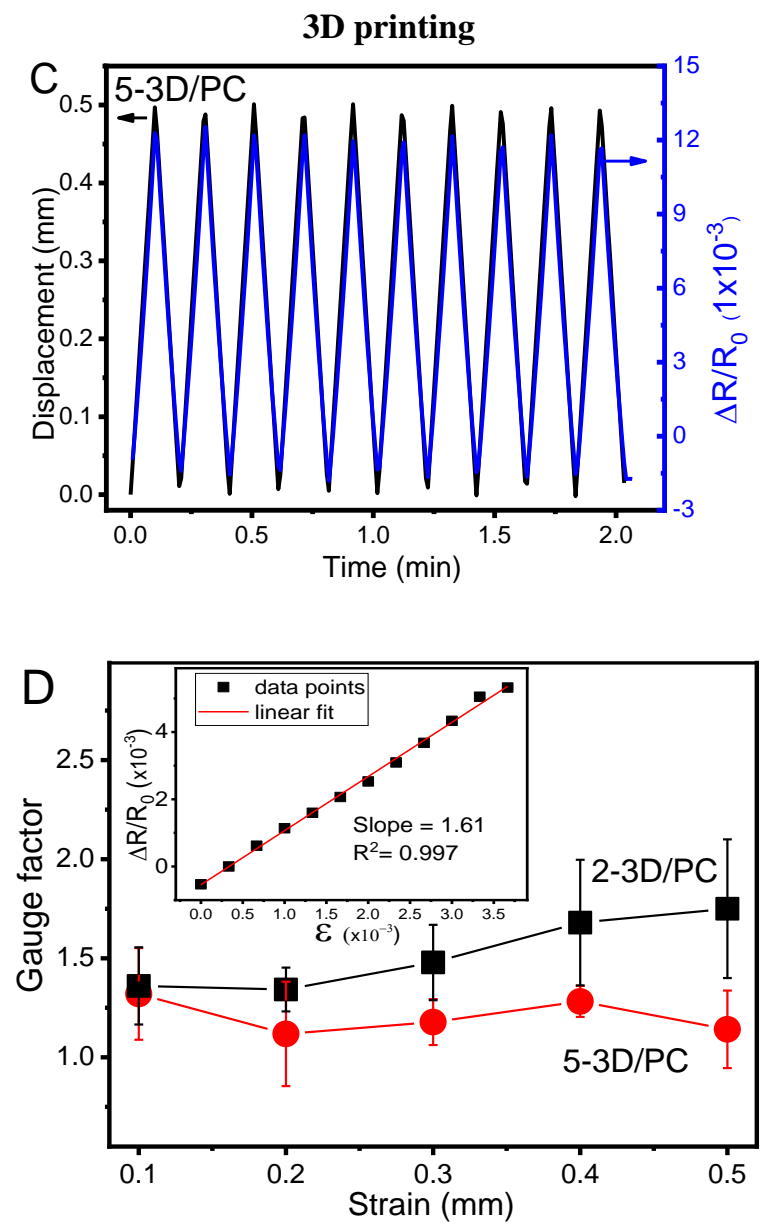

Figure 11- Piezoresistive response of the PC composites prepared by solvent casting (A and B) and 3D printing (C and D) measured under 4-point-bending and uniaxial strain. The piezoresistive measurements were performed up to $6 \mathrm{~mm}$ of displacement in 4-point-bending and $0.5 \mathrm{~mm}$ under uniaxial strain. The fitting of the relative resistance 
variation with applied strain for obtaining the GF is represented in the inset of figure $\mathrm{D}$ ) for the 2-3D/PC sample for $0.5 \mathrm{~mm}$ of strain, as representative of the rest of the samples.

Figure 11 shows the piezoresistive response of the solvent cast and 3D printed composites measured under 4-point-bending and uniaxial strain. Both measures show a linear response of the electrical resistance under applied deformation (Figures 11 A and C). Those represented responses are representative of the remaining sensor materials. The thermoplastic mechanical behaviour of PC and composites (Figure 9) limits the mechanical strain of the functional applicability up to $6 \mathrm{~mm}$ under 4-point-bending and $0.5 \mathrm{~mm}$ under uniaxial stress. The piezoresistive response is larger for uniaxial strain compared to 4-point-bending (Figure $11 \mathrm{~B}$ and D) due to the CNT-CNT contact reconfiguration during external stimulus [55]. The electromechanical response of the materials under 4-pointbending is similar for both processing modes, leading to $0.1<$ GF $<0.4$. The filler content in the samples influences the piezoresistive performance of the materials (Figure 11B), being similar to metals for larger filler contents [55]. The piezoresistive performance of the composites is therefore mostly determined by the geometric factor (Poisson coefficient of PC is about $v \approx 0.37$, leading to a GF geometric contribution of $\approx 1.74$.

Composites near the percolation threshold present larger GF than composites with larger filler contents for uniaxial strain, as the intrinsic resistance variation of the composite is larger for low filler contents $[55,56]$. The piezoresistive response of the composites under uniaxial strain increases slightly with increasing deformation. Under 4-point-bending, the GF is similar for the samples obtained by different processing methods, with different filler contents or applied displacement. This behaviour can be explained if CNT deformation and CNT-CNT distance variations are the dominant mechanisms determining piezoresistive response [55], as in the bending mode, the materials under stimulus present lower displacements, compared to uniaxial strain.

The piezoresistive sensibility is thus larger under uniaxial strain $(1.1<G F<1.75)$ when compared to samples measured under 4-point-bending $(0.1<G F<0.4)$, values that are in agreement with related composites [57].

\section{Self-sensing airplane 3D printed wing model section}

Bases on the obtained composites, a wing model section with self-sensing compatibilities were developed and characterized following two approaches: a) the sensing material (CNT/PC composite) was coated in the structural part, fabricated by $3 \mathrm{D}$ printing of commercial acrylonitrile butadiene styrene (ABS); and b) the whole structure was developed in a self-sensing material (CNT/PC composite).

First, a numerical model was developed to evaluate the sections of the wind model with larger deformations under mechanical loading, allowing to determine the optimized placement of the sensing elements.

\subsection{Numerical simulations}

The numerical simulations allow determining the areas of larger deformation of the structure under compression. When a compressive loading of $5 \mathrm{MPa}$ is applied to the wing, larger deformations occur in specific areas, as illustrated in Figure 12. Further, a path was defined in Abaqus, covering the complete wing's root chord length, along which the values of deformation were plotted (Figure 12). 


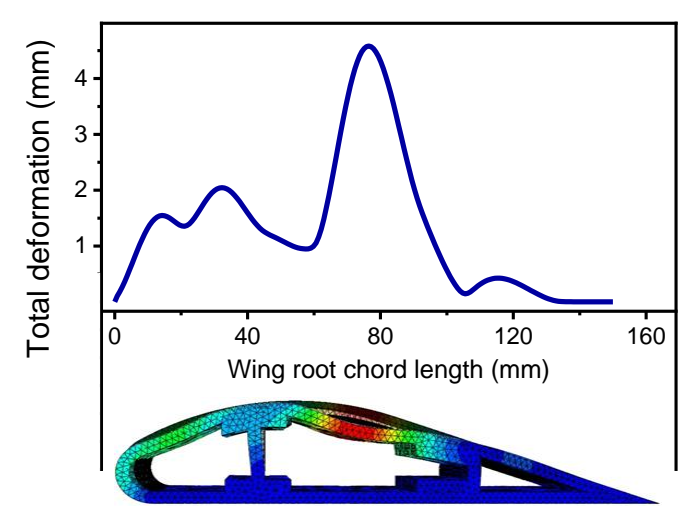

Figure 12- FEM calculation of the deformation along the wing's root chord length under a compressive loading of 5 $\mathrm{MPa}$.

Figure 12 shows that a maximum deformation of $\approx 4.6 \mathrm{~mm}$ is observed when a pressure of $5 \mathrm{MPa}$ is applied on the upper surface of the wing. The deformation varies nonlinearly along the wing's chord, being up to $2 \mathrm{~mm}$ in the stiffeners' zone, and the highest in the central region between the two stiffeners. Thus, the latter zone has been selected to place the sensing materials or the electrodes for monitoring the wing deformation in real-time.

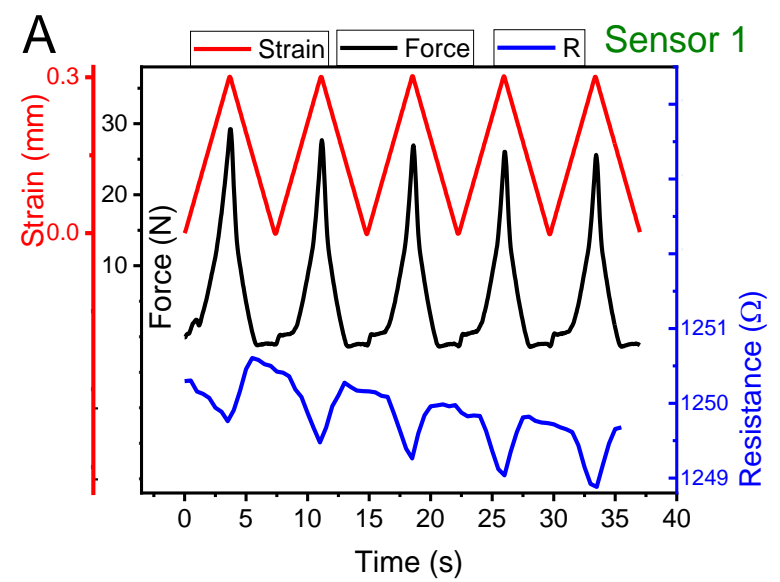

\subsection{Experimental evaluation}

The developed PC composites were used in a prototype using 3 sensors in distinct zones in the airplane wing section fabricated in ABS as supporting material (as shown in Figure 5 and in Figure 13) and in a whole 3D printed (2-3D/PC) composite with sensing properties, presenting similar design and structure. Experimental piezoresistive measurements, shown in Figure 13, were performed in both wing sections in the previously determined most critical zones (Figure 12) under compression deformation of $0.3,0.5$ and $0.7 \mathrm{~mm}$. Figure 13 shows representative examples for sensors $\mathrm{S} 1$ and S2 (see Figure 5) in which a good agreement is verified between the electrical resistance variation and the compression applied to the wing section, at several strains and cycles. Parallel sensors S1 and S3 present similar behaviour (Figure 13A, for S1) and sensor S2 shows larger electrical resistance variation and signal stabilization (as can be observed in Figure 13A and B) once the bending deformation is applied longitudinally to sensor 2 (inset in Figure 13F).

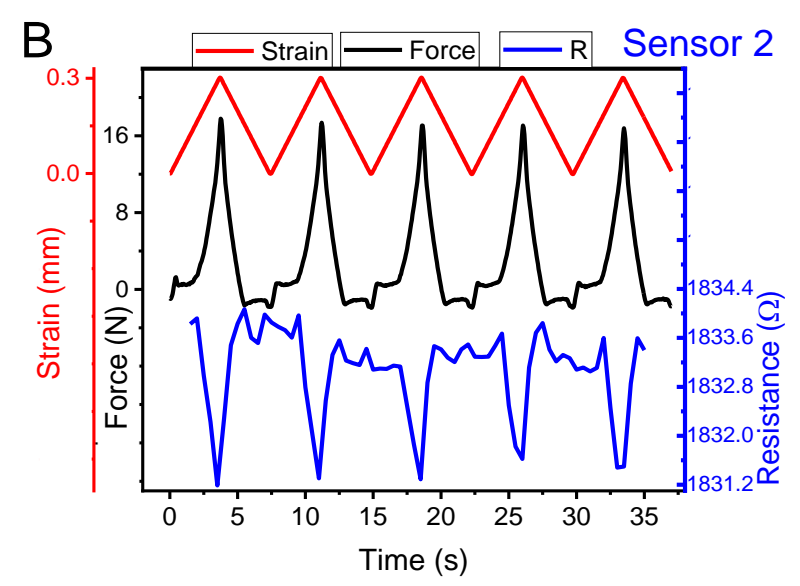



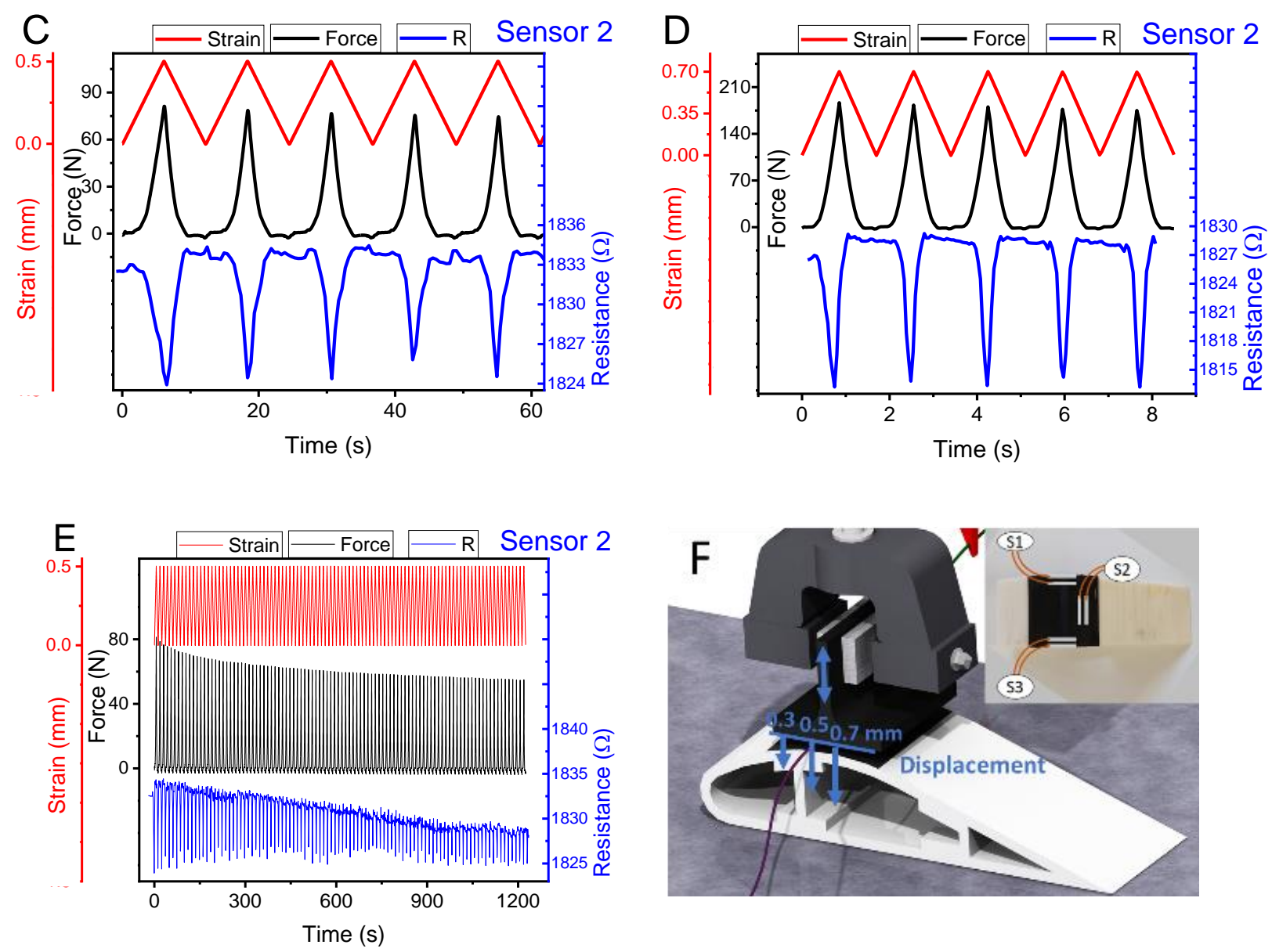

Figure 13- Piezoresistive measurements for 2-3D/PC composite for sensors 1 and 2, applying compressions of $0.3 \mathrm{~mm}$ (A for $\mathrm{S} 1$ and $\mathrm{B}$ for S2), or 0.5 (C) and $0.7 \mathrm{~mm}$ (D) for S2. A larger cycle number is presented for S2 (100 cycles) at $0.5 \mathrm{~mm}$ of compression (E). All measurements were performed at $5 \mathrm{~mm} / \mathrm{min}$ deformation speed for the 2-3D/PC composite. F) Illustration of the piezoresistive measurements in the wing section fabricated by $3 \mathrm{D}$ printing.

As predicted by the piezoresistive response previously characterized and the simulated bending deformation under pressure, the 3D printed wing section shows a good piezoresistive self-sensing response under repeated cycling (Figure 13). The bending movement in the wing is parallel to $\mathrm{S} 2$ and transversal to $\mathrm{S} 1$ and $\mathrm{S} 3$, and for this, $\mathrm{S} 2$ shows larger resistance variation (about $\Delta \mathrm{R} / \mathrm{R}_{0} \approx 0.1 \%$ per cycle) compared to $\mathrm{S} 1$ and $\mathrm{S} 3$ (about $\Delta \mathrm{R} / \mathrm{R}_{0} \approx 0.08 \%$ per cycle) for $0.3 \mathrm{~mm}$ of displacement, as shown in Figure 13A and B. Increasing the force and bending on the wing, the resistance variation increases and $\mathrm{S} 2$ present $\Delta \mathrm{R} / \mathrm{R}_{0} \approx 0.1 \%, \approx 0.5 \%$ and $\approx 0.8 \%$ for $0.3,0.5$ and $0.7 \mathrm{~mm}$ of displacement, respectively, in Figure
13C and D. Under a larger number of deformation cycles, the piezoresistive response is stable, decreasing slightly in the first $70-80$ cycles, tends to stabilize in the following cycles (Figure $13 \mathrm{E})$.

Thus, it is shown that CNT/PC can be tailored to monitor the wing deformation conditions of an airplane wing, working as a sensing material or as SHM, embedded in the wing's structure. Both sensing materials based in 2-3D/PC (whole wing section or coating the ABS structure of wing section) show similar piezoresistive performance up to $0.7 \mathrm{~mm}$ of displacement. Besides, these materials can be manufactured 
by $3 \mathrm{D}$ printing, with great flexibility in the design structure and high definition.

\subsection{Self-sensing wing model with integrated readout electronics}

An electronic circuit was developed to evaluate and communicate in real-time the electrical resistance variations under the applied stimulus. The readout electronics rely on a voltage divider circuit, composed of a reference resistance, which is determined by adjusting a digital potentiometer (Texas Instruments ${ }^{\circledR}$ TPL0501) to the sensor repose resistance (Figure 14a). An analog-to-digital converter present in the PIC32MX230F128L microcontroller from Microchip® is used to measure the voltage variation with sensor excitation. The process of multi-sensing relies on a multiplexer (Texas Instruments ${ }^{\circ}$ CD74HCT4067M) allowing up to 16 channels, while adjusting digital potentiometer value to each sensor to be read. The values are stored in temporary memory with prior system calibration on system power start-up. Furthermore, the system allows USB communication through a serial port by using a USART-USB converter FT232RL from FTDI. In order to allow two types of connection, a $1 \mathrm{~mm}$ pitch ZIF connector from Wurth Elektronics on top and $2.54 \mathrm{~mm}$ receptacle from SAMTEC on the bottom were added to the system, resulting in a printed circuit board as shown in Figure 14B.

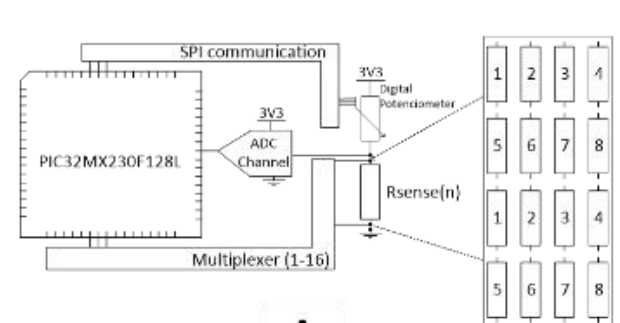

A

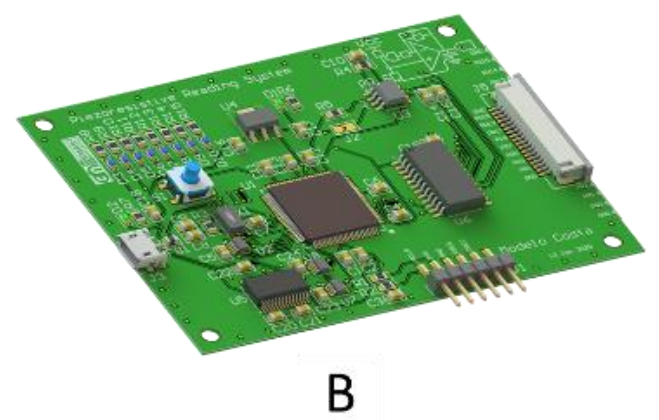

Figure 14-A) Electronic operation principle based on a voltage divider and sensor readout through a multiplexer and B) image of the printed circuit board.

In order to visualise the data, an application with open-source code was built in Qt Designer in C++ UML language, receiving the data and converting them to calculated resistance values, displaying graphs of each sensor simultaneously and exporting the data.

Using the developed electronic system and the sensing wing section structure, the applied displacement (or force) was measured synchronously with the electrical resistance variations for the 3 sensors (S1, S2 and S3 in Figure 15A). All sensors show linear behaviour between applied deformation and electrical resistance variation, for $0.3,0.4$ and $0.5 \mathrm{~mm}$ (corresponding sensibly to 100,150 and $200 \mathrm{~N}$ of force), as presented in Figure 15 for 2-3D/PC. As related in Figure 13, using the wing section with an electronic system and measure synchronously the 3 sensors under the force applied, both sensing wing materials show similar piezoresistive performance. In both cases, the sensing material is the same, just changing the structural materials. Using both approaches, it is demonstrated that $3 \mathrm{D}$ printed and coated piezoresistive materials allow a wide range of application for SHM. 

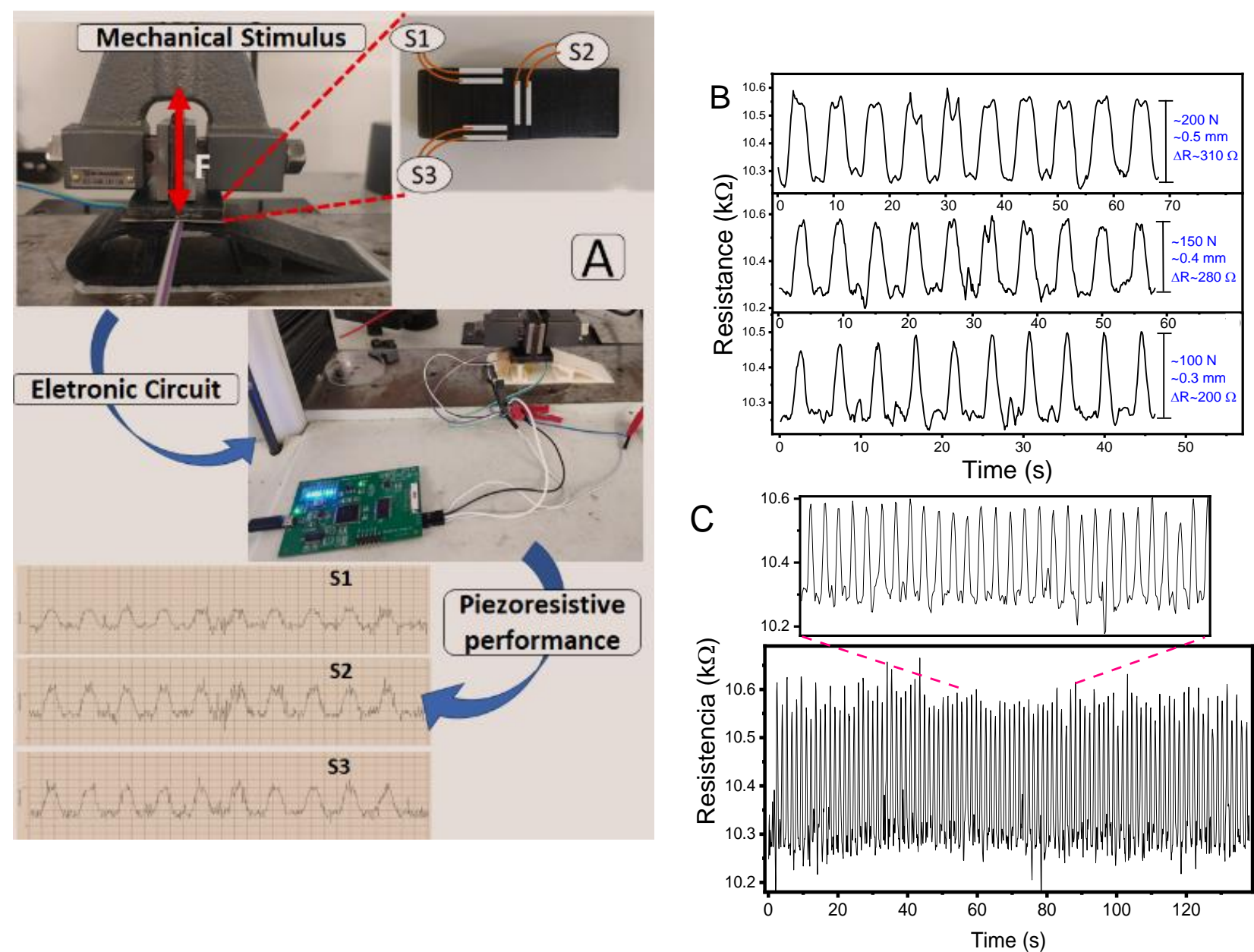

Figure 15-A) Experimental set-up used to measure the self-sensing piezoresistive behaviour of the wing model in the two scenarios developed by $3 \mathrm{D}$ printing and 2-3D/PC as sensing material: wing model fully printed and ABS polymer as support material with 2-3D/PC superimposed in the sensing zone. Piezoresistive measurements for sensor 2 in the ABS/2-3D/PC wing section for A) 10 piezoresistive cycles for $0.3 \mathrm{~mm}, 0.4 \mathrm{~mm}$ and $0.5 \mathrm{~mm}$ applied deformation and C) 100 piezoresistive cycles for $0.4 \mathrm{~mm}$ at $20 \mathrm{~mm} / \mathrm{min}$ deformation speed with an inset to observe the linearity of their piezoresistive response

The electronic systems collect the data points from all sensors, which are visualized in a portable computer in real-time. Figure 15A and B shows the resistance variation as a function of the applied deformation for the 3 different sensors. Increasing the displacement in the prototype, the electrical resistance variation increases, as present in Figure 15B, also showing stability over repeated cycling (Figure 15C). The resistance variation increases with displacement in the wing prototype, from about 200 to $310 \Omega$, as shown in Figure 15B, and is stable for larger cycles number (Figure 15C), changing about $300 \Omega$ per cycle. Thus, it is demonstrated that PC composites with CNT can be applied as SHM materials both in 3D printed structural self-sensing components or as selfsensing coatings in those structures, both approaches demonstrating suitable sensitivity for applications.

\section{Conclusions}

Functional composites were developed by different methods in order to provide self-sensing structural components or coatings. The developed PC-based composites were evaluated in a wing section model, allowing to evaluate force or deformation variations. 
PC polymers reinforced with carbon nanotubes (powder or masterbatch with 15 wt.\% CNTs) were manufactured by solvent casting and 3D printing, as a function of the filler content. Solvent cast films show homogeneous CNTs dispersion and lower electrical percolation threshold (near 0.3 wt.\% CNTs), whereas melt-processed 3D printed films show larger percolation thresholds (near 2 wt.\% CNTs). Mechanical properties of the solvent cast samples reinforced with CNTs slightly increase the elongation at break, with similar yield strain and stress at break. 3D printed samples show lower overall mechanical properties due to $3 \mathrm{D}$ processing and orientation of the filament printing.

The functional performance of the CNT/PC materials is similar for both processing methods, depending on the piezoresistive mode, with GF between $0.1<$ GF $<0.4$ for 4 point-bending experiments and between $1.1<\mathrm{GF}<1.75$ for uniaxial strain mode. Both methods present good linearity between displacement and resistance variation, with 4-pointbending method showing lower piezoresistive response compared to uniaxial strain.

The mechanical deformation of an airplane wing section prototype was simulated in Abaqus, determining the critical zones in compression mode over the wing. Subsequently, a wing section was $3 \mathrm{D}$ printed, to work as a structural health monitoring system. Two approaches were used: the wing section was fabricated entirely in 2-3D/PC and the wing section was fabricated using ABS as support and the 2-3D/PC functional material was placed in the critical regions of the wing section. Both prototypes present excellent mechanical and piezoresistive properties up to $0.5 \mathrm{~mm}$ of vertical displacement, where the electrical resistance follows the applied deformation. Thus, the developed CNT/PC composites can be used for the development of 3D printed self-sensing structural components and/or for the development of printed self-sensing coatings.

\section{Acknowledgements}

This work was supported by the Portuguese Foundation for Science and Technology (FCT) in the framework of the Strategic Funding UID/FIS/04650/2020 and projects UIDB/05549/2020 and TSSiPRO-NORTE-01-0145-FEDER000015. The authors thank the FCT for financial support under SFRH/BPD/110914/2015 (P. C.) and SFRH/BD/121780/2016 (B.F. G.) grants. Financial support from the Basque Government Industry and Education Departments under the ELKARTEK, HAZITEK and PIBA (PIBA-2018-06) programs.

\section{References}

1. Gonzalez-Henriquez, C.M., M.A. SarabiaVallejos, and J. Rodriguez-Hernandez, Polymers for additive manufacturing and 4Dprinting: Materials, methodologies, and biomedical applications. Progress in Polymer Science, 2019. 94: p. 57-116.

2. Vertuccio, L., et al., Piezoresistive properties of resin reinforced with carbon nanotubes for health-monitoring of aircraft primary structures. Composites Part B: Engineering, 2016. 107: p. 192-202.

3. Bekas, D.G., et al., 3D printing to enable multifunctionality in polymer-based composites: A review. Composites Part B: Engineering, 2019. 179: p. 107540.

4. Valino, A.D., et al., Advances in 3D printing of thermoplastic polymer composites and nanocomposites. Progress in Polymer Science, 2019. 98: p. 101162.

5. Lee, J.-Y., J. An, and C.K. Chua, Fundamentals and applications of 3D printing for novel materials. Applied Materials Today, 2017. 7: p. 120-133.

6. Lu, Y., et al., Highly sensitive wearable 3D piezoresistive pressure sensors based on graphene coated isotropic non-woven substrate. Composites Part A: Applied Science and Manufacturing, 2019. 117: p. 202-210.

7. Lazarus, N. and S.S. Bedair, Creating 3D printed sensor systems with conductive composites. Smart Materials and Structures, 2020. 30(1): p. 015020.

8. Gnanasekaran, K., et al., 3D printing of CNTand graphene-based conductive polymer nanocomposites by fused deposition modeling. Applied Materials Today, 2017. 9: p. 21-28. 
9. Chung, D.D.L., A review of multifunctional polymer-matrix structural composites. Composites Part B: Engineering, 2019. 160: p. 644-660.

10. Deng, H., et al., Progress on the morphological control of conductive network in conductive polymer composites and the use as electroactive multifunctional materials. Progress in Polymer Science, 2014. 39(4): p. 627-655.

11. Gupta, S., A. Sharma, and R.S. Verma, Polymers in biosensor devices for cardiovascular applications. Current Opinion in Biomedical Engineering, 2020. 13: p. 69-75.

12. Alarifi, I.M., Investigation the conductivity of carbon fiber composites focusing on measurement techniques under dynamic and static loads. Journal of Materials Research and Technology, 2019. 8(5): p. 4863-4893.

13. García-Macías, E., et al., Micromechanics modeling of the uniaxial strain-sensing property of carbon nanotube cement-matrix composites for SHM applications. Composite Structures, 2017. 163: p. 195-215.

14. Falletta, E., et al., Development of high sensitive polyaniline based piezoresistive films by conventional and green chemistry approaches. Sensors and Actuators A: Physical, 2014. 220: p. 13-21.

15. Lu, Y., et al., Recent developments in biomonitoring via advanced polymer nanocomposite-based wearable strain sensors. Biosensors and Bioelectronics, 2019. 123: $p$. 167-177.

16. Wang, X., et al., Highly sensitive and stretchable piezoresistive strain sensor based on conductive poly(styrene-butadienestyrene)/few layer graphene composite fiber. Composites Part A: Applied Science and Manufacturing, 2018. 105: p. 291-299.

17. Costa, P., et al., Electro-mechanical properties of triblock copolymer styrene-butadienestyrene/carbon nanotube composites for large deformation sensor applications. Sensors and Actuators A: Physical, 2013. 201: p. 458-467.

18. Teixeira, J., et al., Piezoresistive response of extruded polyaniline/(styrene-butadienestyrene) polymer blends for force and deformation sensors. Materials \& Design, 2018. 141: p. 1-8.

19. Li, J., et al., Review-Recent Progress in Flexible and Stretchable Piezoresistive Sensors and Their Applications. Journal of The Electrochemical Society, 2020. 167(3): p. 037561.

20. van de Werken, N., et al., Additively manufactured carbon fiber-reinforced composites: State of the art and perspective. Additive Manufacturing, 2020. 31: p. 100962.

21. Castro, H.F., et al., Printed Wheatstone bridge with embedded polymer based piezoresistive sensors for strain sensing applications. Additive Manufacturing, 2018. 20: p. 119-125.

22. Mittal, S., et al., A critical review of smart manufacturing \& Industry 4.0 maturity models: Implications for small and medium-sized enterprises (SMEs). Journal of Manufacturing Systems, 2018. 49: p. 194-214.

23. Ye, M.H., et al., Graphene Platforms for Smart Energy Generation and Storage. Joule, 2018. 2(2): p. 245-268.

24. Fiorillo, A.S., C.D. Critello, and S.A. Pullano, Theory, technology and applications of piezoresistive sensors: A review. Sensors and Actuators A: Physical, 2018. 281: p. 156-175.

25. Dong, W., et al., Piezoresistive properties of cement-based sensors: Review and perspective. Construction and Building Materials, 2019. 203: p. 146-163.

26. Haghgoo, M., M.K. Hassanzadeh-Aghdam, and R. Ansari, A comprehensive evaluation of piezoresistive response and percolation behavior of multiscale polymer-based nanocomposites. Composites Part A: Applied Science and Manufacturing, 2020. 130: p. 105735.

27. Abbasi, H., M. Antunes, and J.I. Velasco, Recent advances in carbon-based polymer nanocomposites for electromagnetic interference shielding. Progress in Materials Science, 2019. 103: p. 319-373.

28. Gao, X., et al., Influence of processing parameters during ultrasound assisted extrusion on the properties of polycarbonate/carbon nanotubes composites. Composites Science and Technology, 2017. 144: p. 125-138. 
29. Bernardo, M., et al., Toxicity of char residues produced in the co-pyrolysis of different wastes. Waste Management, 2010. 30(4): p. 628-635.

30. Tundo, P., M. Musolino, and F. Aricò, The reactions of dimethyl carbonate and its derivatives. Green Chemistry, 2018. 20(1): p. 28-85.

31. ASTM D638-14, Standard Test Method for Tensile Properties of Plastics. 2014: West Conshohocken, PA,

32. Stassi, S., et al., Smart piezoresistive tunnelling composite for flexible robotic sensing skin. Smart Materials and Structures, 2013. 22(12): p. 125039.

33. Dios, J.R., et al., Piezoresistive performance of polymer-based materials as a function of the matrix and nanofiller content to walking detection application. Composites Science and Technology, 2019. 181: p. 107678.

34. Lin, L., et al., Modified resistivity-strain behavior through the incorporation of metallic particles in conductive polymer composite fibers containing carbon nanotubes. Polymer International, 2013. 62(1): p. 134-140.

35. Cardoso, J.V., P.V. Gamboa, and A.P. Silva, Effect of surface pre-treatment on the behaviour of adhesively-bonded CFRP T-joints. Engineering Failure Analysis, 2019. 104: p. 1188-1202.

36. Wehrmann, R., Polycarbonate, in Encyclopedia of Materials: Science and Technology, K.H.J. Buschow, et al., Editors. 2001, Elsevier: Oxford. p. 7149-7151.

37. Systèmes, D. Abaqus Analysis User's Manual. 2008 [cited 2020 July]; 18.2.1 Linear elastic behavior]. Available from:

http://130.149.89.49:2080/v6.8/books/usb/de fault.htm?startat=pt05ch18s02abm02.html\#us b-mat-clinearelastic-isotropic.

38. Takeda, T., et al., Tensile Characterization of Carbon Nanotube-Reinforced Polymer Composites at Cryogenic Temperatures: Experimens and Multiscale Simulations. MATERIALS TRANSACTIONS, 2009. 50(3): p. 436-445.

39. Ma, P.-C., et al., Dispersion and functionalization of carbon nanotubes for polymer-based nanocomposites: A review.
Composites Part A: Applied Science and Manufacturing, 2010. 41(10): p. 1345-1367.

40. Ghazzawi, Y.M., A.F. Osorio, and M.T. Heitzmann, The effect of fibre length and fibre type on the fire performance of thermoplastic composites: The behaviour of polycarbonate as an example of a charring matrix. Construction and Building Materials, 2020. 234: p. 117889.

41. Baek, Y.-M., et al., Thermal transfer, interfacial, and mechanical properties of carbon fiber/polycarbonate-CNT composites using infrared thermography. Polymer Testing, 2020. 81: p. 106247.

42. Lago, E., et al., Solution blending preparation of polycarbonate/graphene composite: boosting the mechanical and electrical properties. RSC Advances, 2016. 6(100): p. 97931-97940.

43. Sinha, D., et al., Gamma-induced modifications of polycarbonate polymer. Radiation Effects and Defects in Solids, 2004. 159(10): p. 587595.

44. Behboudi, A., Y. Jafarzadeh, and R. Yegani, Polyvinyl chloride/polycarbonate blend ultrafiltration membranes for water treatment. Journal of Membrane Science, 2017. 534: p. 18-24.

45. Feng, Y., et al., A facile strategy for functionalizing silica nanoparticles by polycarbonate degradation and its application in polymer nanocomposites. Polymer Degradation and Stability, 2015. 119: p. 295298.

46. Parshin, A.M., et al., Domain structures in nematic liquid crystals on a polycarbonate surface. International journal of molecular sciences, 2013. 14(8): p. 16303-16320.

47. Feng, J., et al., Using TGA/FTIR TGA/MS and cone calorimetry to understand thermal degradation and flame retardancy mechanism of polycarbonate filled with solid bisphenol $A$ bis(diphenyl phosphate) and montmorillonite. Polymer Degradation and Stability, 2012. 97(4): p. 605-614.

48. Shen, B., et al., Enhanced interfacial interaction between polycarbonate and thermally reduced graphene induced by melt blending. Composites Science and Technology, 2013. 86: p. 109-116. 
49. Kim, K.H. and W.H. Jo, A strategy for enhancement of mechanical and electrical properties of polycarbonate/multi-walled carbon nanotube composites. Carbon, 2009. 47(4): p. 1126-1134.

50. Yap, Y.L., et al., A non-destructive experimental-cum-numerical methodology for the characterization of 3D-printed materialspolycarbonate-acrylonitrile butadiene styrene (PC-ABS). Mechanics of Materials, 2019. 132: p. 121-133.

51. Park, S.J., et al., 3D printing of bio-based polycarbonate and its potential applications in ecofriendly indoor manufacturing. Additive Manufacturing, 2020. 31: p. 100974.

52. Yuan, S., et al., Polymeric composites for powder-based additive manufacturing: Materials and applications. Progress in Polymer Science, 2019. 91: p. 141-168.

53. Li, $\mathrm{Y}$., et al., Electrical and vapor sensing behaviors of polycarbonate composites containing hybrid carbon fillers. European Polymer Journal, 2018. 108: p. 461-471.

54. Zhi, X., et al., Electrically conductive polycarbonate/carbon nanotube composites toughened with micron-scale voids. Carbon, 2015. 82: p. 195-204.

55. Gong, S. and Z.H. Zhu, On the mechanism of piezoresistivity of carbon nanotube polymer composites. Polymer, 2014. 55(16): p. 41364149.

56. Souri, H., et al., A theoretical study on the piezoresistive response of carbon nanotubes embedded in polymer nanocomposites in an elastic region. Carbon, 2017. 120: p. 427-437.

57. Robert, C., J.F. Feller, and M. Castro, Sensing Skin for Strain Monitoring Made of PC-CNT Conductive Polymer Nanocomposite Sprayed Layer by Layer. ACS Applied Materials \& Interfaces, 2012. 4(7): p. 3508-3516. 